\title{
Corrections
}

\section{Correction: Oemisch et al., Interareal Spike-Train Correlations of Anterior Cingulate and Dorsal Prefrontal Cortex during Attention Shifts}

In the article "Interareal Spike-Train Correlations of Anterior Cingulate and Dorsal Prefrontal Cortex during Attention Shifts" by Mariann Oemisch, Stephanie Westendorff, Stefan Everling, and Thilo Womelsdorf, which appeared on pages 13076-13089 in the September 23, 2015 issue, the authors regret an error in Figure $2 B$, where the $y$-axis has been accidentally mislabeled. The $y$-axis representing the average correlation of spiking activity should range from -0.01 to 0.02 , instead of the falsely represented range of -0.001 to 0.002 . All other figures are correctly displayed. This error does not affect any conclusions or interpretations of the paper. The correct Figure 2 is shown below.

A

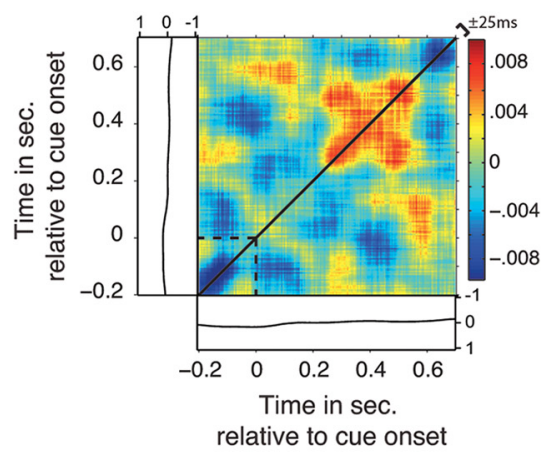

C

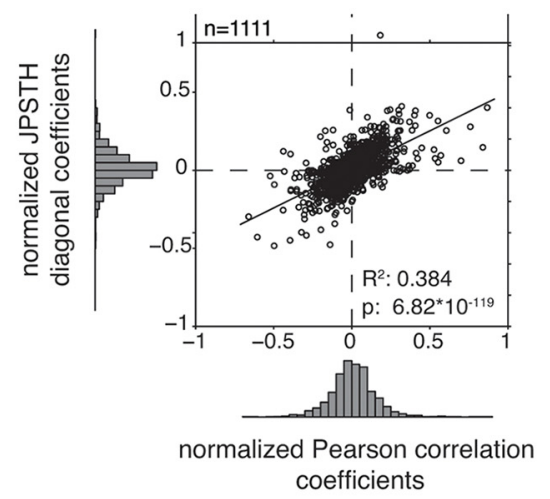

E

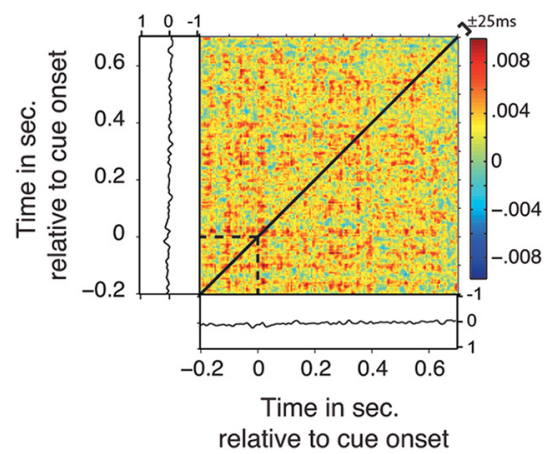

B

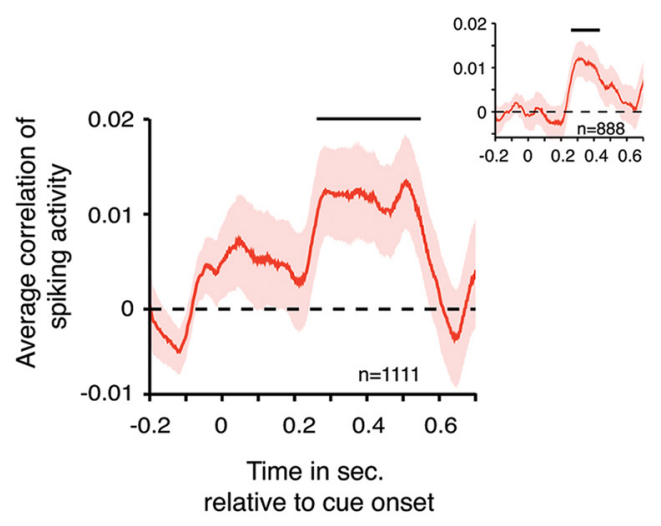

D

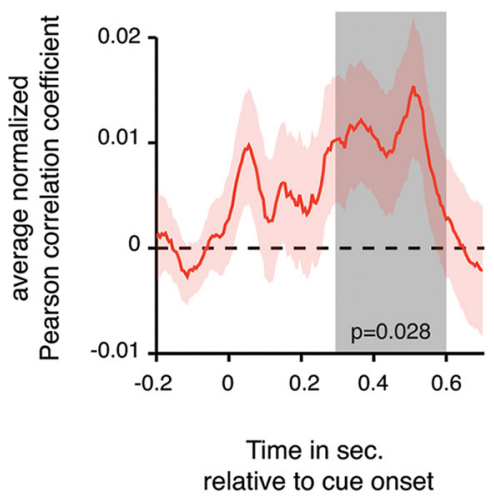

$\mathbf{F}$

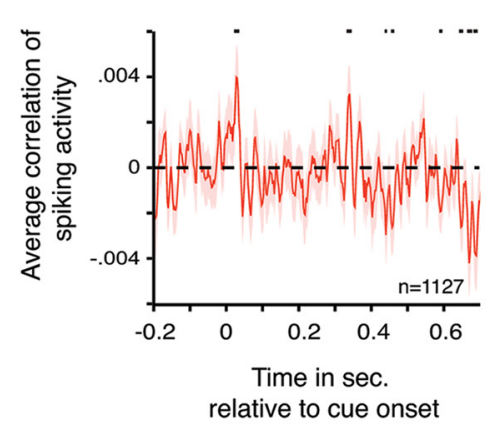

Figure 2. 